GONORRHEAL OPHTHALMIA IN A CHILD OF TWO YEARS.

\author{
JoHx A. MCCAw. M.D., \\ DENVER, COIO.
}

A girl two years of age was admitted to the Denver City and County IIospital with an infection of both eyes. The eyelids were chemotic and closed. A thick creamy pus was being exuded from eyes. The clinical appearances were those of ophthalmia neonatorum. The laboratory report stated the infecting organism was a gram negative, intracellular diplococcus.

When the child was admitted, the chief resident interne ordered that the eyes be cleansed with warm boric solution every two hours, and constant application of cold compresses. $125 \%$ solution of argyrol freshly prepared daily, was instilled in the eyes every two hours. Six days after the child was admitted, I saw the patient for the first time. The eyelids of both eyes were edematous and closed and there was a fairly profuse discharge from the eyes. I did not succeed in getting a view of the cornea.

In addition to the treatment that was being given we suggested that a $5 \%$ silver nitrat solution be applied once to the everted lids. After five days, there being no decided change in the condition, I stopped the argyrol and prescribed mercurochrom 1\%, four times daily. Four days later the discharge was still profuse tho thinner and more watery. Smears taken at this time showed a gram negrative intracellular diplococcus characteristic of gonococcus, but with less mucus in the smear.

The laboratory report notwithstanding, I felt that we must be dealing with a mixed infection; so I ordered the mercurochrom discontinued and prescribed zinc sulphat grs. 2 , boric acid grs. 5 , tr. of opium, dram 1, to aqua clestillata f. ounce 1. Two drops in each eye every two hours. The irrigation and cold compresses were continued.

In forty-eight hours the discharge was completely checked and the child had both cyes open and in another day the eyes appeared perfectly normal and the patient was discharged. The tr. of opium added to this prescription, has a mild astringent as well as anodyne effect, and increases the tolerance for the rinc sulphat in this strength.

\section{CORNEAL ULCER FOLLOWING APPLICATION OF TONOMETER.}

Walter J. Gilbert, M.D.,

CAIAIS, MAINE.

The June number of Ophthalmic I.iterature, quoting from Elliot's address before the British Society, states that great care should be exercised in using the tonometer, as complications may arise from traumatizing the corneal epithelium.

Within a short time the writer has had an experience demonstrating that the above advice is not wholly theoretic. $\mathrm{Mr}$. J. H., age 76 , a patient in Chipman Memorial Hospital, St. Stephen, $N$. B., while convalescing from a prostatectomy complained of failing vision extending over a period of one year. The attending surgeon, Dr. W. H. Bunker of Calais immediately referred the case. An ophthalmic examination revealed chronic noninflammatory glaucoma. In using the tonometer the following technic was carried out. Irrigations with warm saturated solution boric acid, 4\% protargol and holocain for anesthesia. 'The piston of the foot plate was cleaned with alcohol, then sterile water and petrolatum. After readings, bichlorid ointment was instilled between the lids.

As the patient was a high strung, nervous man, a protective bandage was applied. Fxamination was made at eight A. M. The following day, the nurse had charted "patient complains of pain and discomfort in right eye." At nine A. M.. or twenty-four hours after examination, the eye had well marked subjective symptoms of ulceration, and in forty-eight hours there was no question as to the condition we had to deal with. The treatment consisted in cauterizing the area, outlined by fluorescein solution, fomentations and frequent instillations of mercurochrome $1 \%$. Both eyes were kept bandaged 
during the intervals between treatments and the patient made a good recovery.

One of my colleagues suggested an impending ulceration before examination, but there were no symptoms to substantiate this. It would be well to state that the same morning two other patients had tonometric readings, but not the slightest complication arose from examination of these patients.

The object of reporting this case is to emphasize the importance of Elliot's suggestion: That is, keeping old people under observation for at least twenty-four hours after tonometry.

\section{DETACHMENT OF THE RETINA} FOLLOWING INTRACAPSULAR CATARACT EXTRACTION.

Wallace Ralstox, M.D., F.A.C.S.. and

$$
\text { E. L. Goar, A.B., M.D., }
$$

HOUSTON, TEXAS.

The following case is reported for the reason that, judging from the literature and from conversations with advocates of the Smith-Indian operation, it is a very unusual sequela. In a recent conversation with one of the leading American exponents of this method, we were informed that he had never seen this unfortunate complication.

J. F., age 71 , retired merchant. Had lens extracted from right eye two years ago. With correction vision right eye $20 / 50$, left eye light projection perfect. Has a slight secondary in right eye, in the left a mature cataract. Well nourished man. Has moderate degree of pyorrhea. Urinalysis was negative. Teeth and gums were put in good condition by dentist. May 18, 1921, cataract extraction was done on left eye by the Smith-Indian method. No undue pressure on cornea was necessary for expression. There was no loss of vitreous and operation was uneventful. Dressed first on 7 th day. There was very little injection. The pillars of the coloboma were free. Anterior chamber had not formed and iris was in apposi- tion to posterior surface of the cornea. On the 9th day there was still no anterior chamber. A grayish mass was noted forward on the temporal side, easily visible by oblique illumination and having the typical appearance of a retinal detachment. Three days later the same condition appeared on the nasal side. June 4th, sixteen days after operation, the gibbous protrusion appeared above and bclow, forming four distinct projections. The eye was still soft, very little injected and there was no anterior chamber. The first evidence of the reforming of the anterior chamber occurred June 11 th, twentythree days after operation. By June 20 th the detachment had disappeared above and below and was less marked laterally and mesially. The anterior chamber remained shallow and the tension low until about July 5 th, tho there was no evidence of detachment seen on June 25 th. On July 11 th there was a good anterior chamber, very little injection, and the tension was normal by palpation. Some small retinal hemorrhages were visible with the ophthalmoscope and the fact that one of these was in the macular region may explain why this patient's vision was never better than 20/100 with correction.

It is worthy of note that altho the prolonged absence of the anterior chamber pointed to a choroidal detachment, the protrusions had the typical form and color of detachment of the retina. Also that aside from a few vertical striac which rapidly disappeared, the cornca was apparently uninjured by its prolonged apposition to the iris.

\section{AMULETS FOR THE CURE OF DISEASES OF THE EYES.}

Harry Friedenwald, M.D.,

BALTIMORE, MD.

Amulets played a leading part in the treatment of disease, in ancient and in medieval times. "Over vast regions of the earth to-day, magic amulets, charms, incantations are the chief weapons of defense against a malignant Nature." (Osler.)

The eye has enjoyed special favor, and 